\title{
Risks of the Meiliang Bay Source of Drinking Water in Taihu Lake (MLB- SDW-THL) on Environmental Health
}

\author{
Shifeng Yun ${ }^{1}$, Xiaoyun Tian ${ }^{1}$, Shupei Cheng ${ }^{2 *}$, Yan Zhang ${ }^{2}$, Libo Zhang ${ }^{1}$, Li Chen ${ }^{1}$, Lianqin Guo ${ }^{1}$, Hongling Zhang ${ }^{3}$, Fei He ${ }^{3}$, Weixin Li ${ }^{* *}$ and \\ Yunzhong Shi ${ }^{4}$
}

${ }^{1}$ Department of Comparative Medicine, Jinling Hospital, 305 Zhongshang Donglu, Nanjing 210002, China

${ }^{2}$ State Key Laboratory of Pollution Control \& Resource Reuse, School of the Environment Sciences, Nanjing University (Xianlin Campus), 163 Xianlin Dadao, Nanjing, 210046, China

${ }^{3}$ Nanjing Institute of Environmental Science, The State Environmental Protection Administration (SEPA), Nanjing, 210042, China

${ }^{4}$ Nanjing University of Chinese Medicine, 138 Xianlin Dadao, Nanjing, 210046, China

\begin{abstract}
There was a cyanobacteria bloom occurred in the area of Meiliang Bay source of drinking water in Taihu Lake (MLB-SDW-THL) in 2007 when MLB-SDW-THL couldn't be used to make a tap water for people drinking and washing. Three years later, whether MLB-SDW-THL had biochemical effects on the mouse serum was researched for predication of its risks on human and environmental health. The water samples of MLB-SDW-THL were taken at N31.53 and E120.21 in March of 2010 and kept at $4^{\circ} \mathrm{C}$ for the experiment. Measurement of 22 organic pollutants with DSQ II Single Quadruple GC/MS in selected ion monitoring (SIM) indicated that 11 of them were discovered in MLBSDW-THL. Mice Mus musculus were fed with MLB-SDW-THL for $90 \mathrm{~d}$ under standard conditions. The eighteen serum biochemical parameters, the clinical parameters used in China hospitals, were measured by Automatic Biochemical Analysis/RerLi 600 and the parameter data treated by One-Way ANOVA statistic approach. The results showed that among the measured eighteen serum biochemical parameters, six of the 18 parameter levels were decreased significantly $(0.01<\mathrm{P}$ or $0.05<\mathrm{P})$ including alanine transaminase (ALT, $57 \%$ lower), aspartate aminotransferase (AST $36 \%$ lower); cystatin C (Cys C, 25\% lower); triglycerol (TG, $79 \%$ lower); high density lipoprotein-cholesterol (HDL-C, $12 \%$ lower); and lipase (LPS, 16\% lower). It indicated that the MLB-SDW-THL had biochemical toxicities on the serum of mouse Mus musculus which might induce metabolism disorders, liver and kidney diseases, cardiovascular diseases, brain disorders, pancreas diseases and survival year reduced in the elderly people et al. The data suggest that the biochemical risks might be mainly from PAHs and di-n-butyl phthalate discovered at least in MLB-SDW-THL which should be controlled for protection of human and environmental health.
\end{abstract}

Keywords: Taihu lake; Meiliang bay; Source water, Mus musculus; Serum parameter; Biochemical risk

\section{Introduction}

During a cyanobacteria bloom occurred in 2007, the Meiliang Bay source of drinking water in Taihu Lake (MLB-SDW-THL) couldn't be used to produce tap water as drinking water and washing clothes because this tap-water had very bed smell. So, the project of Water Environmental Risk Evaluation and Precaution Technology in Taihu Lake Area (WEREPT-THA) was enlisted in 2008 funded by China government. Since then, many research results in ecological toxicity of MLB-SDW-THL were reported such as by Qian et al. [28], Huang et al. [17], Li et al. [22], Li et al. [23].

This study is one part of the program WEREPT-THA targeted to find out whether the MLB-SDW-THL still had biochemical risks and whether it could be used as a source of drinking water now. It was based on the measurement of eighteen serum biochemical parameters which are the clinical parameters used in Chinese hospitals to make diagnosis. The data obtained in this research indicated that the biochemical risks existed in MLB-SDW-THL which will be discussed in this paper.

\section{Materials and Methods}

\section{Measuring organic pollutants}

5 liter samples of MLB-SDW-THL were taken at N31.53 and E120.21 in March of 2010 and kept at $4^{\circ} \mathrm{C}$ for the experiment. Measurement of 22 organic pollutants by Nanjing Institute of Geography and Limnology of Chinese Academy of Sciences, with DSQ II Single Quadruple GC/MS (ThermoQuest, San Jose, CA, USA) in selected ion monitoring (SIM) mode, indicated that 11 of them were discovered in the water shown in Table 1 . These 22 organic pollutants measured were (1) isophorone, (2) hexachlorocyclopentadiene, (3) dimethyl phthalate, (4) acenaphthylene, (5) 2,4-dinitrotoluene, (6) fluorine, (7) hexachlorobenzene, (8) anthracene, (9) phenanthrene, (10) di-n-butyl phthalate, (11) pyrene, (12) benzyl butyl phthalate, (13) bis-2-ethylhexyl adipate, (14) chrysene-d12, (15) benzo (a) anthracene, (16) bis(2-ethylhexyl)phthalate, (17) benzo(b)fluoranthene, (18) benzo(k)fluoranthene, (19) benzo(a)pyrene, (20) benzo(g,h,i)perylene, (21) indeno(1,2,3-cd)pyrene, and (22) dibenz(a,h)anthracene.

\section{Sampled animal treatment}

Sixty of 21-day-old male mice Mus musculus were randomly divided in two groups, sample group and control group. The mice in

*Corresponding authors: Shupei Cheng, State Key Laboratory of Pollution Control \& Resource Reuse, School of the Environment Sciences, Nanjing University (Xianlin Campus), 163 Xianlin Dadao, Nanjing, 210046, China, Tel: 8625-89680368; Fax:86-25-89680569; E-mail: chengsp@nju.edu.cn

Weixin Li, Nanjing Institute of Environmental Science, The State Environmental Protection Administration of china, Nanjing, 210042, China, E-mail: Iwxletter@ yahoo.com.cn

Received June 06, 2011; Accepted August 04, 2011; Published August 06, 2011

Citation: Yun S, Tian X, Cheng S, Zhang Y, Zhang L, et al. (2011) Risks of the Meiliang Bay Source of Drinking Water in Taihu Lake (MLB-SDW-THL) on Environmental Health. J Bioequiv Availab 3: 165-168. doi:10.4172/jbb.1000078

Copyright: (c) 2011 Yun S, et al. This is an open-access article distributed under the terms of the Creative Commons Attribution License, which permits unrestricted use, distribution, and reproduction in any medium, provided the original author and source are credited. 
the sample group were fed with MLB-SDW-THL sample and that in the control group were fed with clean bottled water bought in the NJ supermarket. The feeding time for both groups lasted from March 16 to June 16 in 2010 for 90 days.

10 mice were housed in each cage at the Animal Center of Academy of MMS Laboratory in a $12 / 12 \mathrm{~h}$ light/dark cycle, at $22 \pm 2^{\circ} \mathrm{C}$ and $50 \pm$ $5 \%$ relative humidity. After 90 -day treatment, their blood was collected in accordance with the Guide for the Care and Use of Laboratory Animals of National Institutes of Health (NIH) (National Research Council, 1996) and stored in tubes overnight. Then the sera samples were obtained with centrifuge $\left(3,500 \mathrm{rpm}, 10 \mathrm{~min}\right.$ at $\left.4^{\circ} \mathrm{C}\right)$, and then eighteen biochemical parameters were detected.

\section{Serum parameter measurement}

Many methods can be used to measure the serum biochemical parameters such as reported by Chan et al. [7], Reidy et al. [30], Maresova et al. [24], Han et al. [16] and Zhao et al. [44]. In this research, the eighteen serum biochemical parameter levels for the sampled mice were measured by Automatic Biochemical Analysis/ RerLi 600 (Japan Product). And their data were treated by OneWay ANOVA statistic approach. These eighteen serum biochemical parameters measured in this research have been used in Chinese hospitals as important evidences for making the clinical diagnosis including (1) total protein (TP), (2) globulin, (3) albumin (ALB), (4) creatinine (Cr), (5) uric acid (UA), (6) cystatin C (Cys C), (7) gammaglutamyl transpeptidase (GGT), (8) lactate dehydrogenase (LDH), (9) triglycerol (TG), (10) serum urea (SU), (11) cholesterol, (12) highdensity lipoprotein cholesterol (HDL-C), (13) low-density lipoprotein cholesterol (LDL-C), (14) alanine transaminase (ALT, formerly termed serum glutamic pyruvic transaminase (SGPT) or glutamicpyruvic transaminase, GPT), (15) aspartate aminotransferase (AST, formerly termed serum glutamic-oxaloacetic transaminase, SGOT, or glutamic-oxaloacetic transaminase, GOT), (16) amylase (AMS), (17) lipase (LPS) and (18) alkaline phosphatase (ALP). Of the eighteen serum biochemical parameter levels, six were decreased by the water discovered shown in Table 2.

\section{Results and Discussion}

The data in Table 2 listed the six biochemical parameters that were significantly lower in the animals exposed to the source of drinking water sample of MLB-SDW-THL and the related each parameter to potential risk on human health listed in Table 3.

\section{Risk analysis for ALT \& AST}

The level of alanine transaminase (ALT) in the sample group was $57 \%(\mathrm{P}<0.01)$ lower than that of the control shown in Table 2. ALT is an intracellular enzyme involved in amino acid and carbohydrate metabolism. It is present in high concentrations in muscle, liver

\begin{tabular}{|l|l|l|l|}
\hline Organic pollutants & $\begin{array}{l}\text { Concentrations } \\
(\mu \mathrm{g} / \mathrm{L})\end{array}$ & Organic pollutants & $\begin{array}{l}\text { Concentrations } \\
(\mu \mathrm{g} / \mathrm{L})\end{array}$ \\
\hline isophorone & 2648.88 & phenanthrene & $22.26^{* *}$ \\
\hline dimethyl phthalate & 648.71 & di-n-butyl phthalate & 3632.46 \\
\hline acenaphthylene & 3.89 & pyrene & $46.68^{* *}$ \\
\hline $2,4-$ dinitrotoluene & 107.31 & bis-2-ethylhexyl adipate & 2857.07 \\
\hline fluorene & $261.06^{* *}$ & bis(2-ethylhexyl)phthalate & 3748.50 \\
\hline anthracene & $95.28^{* *}$ & - & - \\
\hline
\end{tabular}

Note: Each value in Table 1 is the mean of three MLB-SDW-THL samples. ${ }^{* *}$ Four organic pollutants are PAHs discovered in the MLB-SDW-THL sample

Table 1: The concentrations of eleven organic pollutants discovered in MLB-SDWTHL. and brain. Its measurement is most commonly used as part of the differential diagnosis of liver disease and in the tracking of the course of the disease process. An increased level of ALT in the blood indicates necrosis or disease in these tissues $[9,40]$.

The level of aspartate transaminase (AST) in the sample group was $36 \%(\mathrm{P}<0.01)$ lower than that of the control shown in Table 2. AST is another intracellular enzyme involved in amino acid and carbohydrate metabolism. It is present in high concentrations in muscle, liver and brain. An increased level of AST in the blood indicates necrosis or disease in these tissues $[10,40]$.

Table 3 indicated that lower than normal levels of ALT are found to be associated with reduced survival year in the elderly people [21] And reduced levels of ALT and AST might indicate disorders in amino acid and carbohydrate metabolism due to their gene transcription expressions or/and protein expressions disturbed [34]. ALT and AST should remain at a steady level in the blood for a healthy person.

\section{Risk analysis for Cys C}

The level of cystatin C (Cys C) in the sample group was 25\% lower than that of the control $(\mathrm{P}<0.01)$ shown in Table 2. Cys $\mathrm{C}$ is a protease inhibitor synthesized in all nucleated cells. It is found in virtually all tissues and bodily fluids and works as a chain of 120 amino acids $[5,37]$. Cys C is mainly used as a biomarker of kidney function, and in predicting new-onset or deteriorating cardiovascular diseases and brain disorders involving amyloid. Its ultimate clinical utility has yet to be fully established $[3,19,31,32,36]$. Since Cystatin C is produced throughout the body at a constant rate and removed and broken down by the kidneys, it should remain at a steady level in the blood if the kidneys are working efficiently and the glomerular filtration rate (GFR) is normal [3].

Table 3 indicates that the decreased Cys $\mathrm{C}$ levels associated with atherosclerosis and aortic aneurysms. Breakdown of parts of the vessel wall in these conditions result from an imbalance between proteinases and their inhibitors $[1,2,14,33,35]$.

\section{Risks analysis for TG}

The level of triglycerol (TG) in the Sample Group was $79 \%$ lower than that of the control $(\mathrm{P}<0.01)$ shown in Table 2. TGs are the resulted substances of triglyceride, any combinations of glycerol and three of five fatty acids. TGs are widespread in adipose tissue, and commonly circulate in the blood in the form of lipoproteins. The liver synthesizes lipoproteins to transport fats to other tissues, where they are a source of energy. Therefore, TGs play an important role in metabolism as energy sources and transporters of dietary fat $[18,25,40]$.

Table 3 indicates that lower than normal level of TG has been found to be associated with hyperthyroidism and mal-absorption syndrome [9].

\section{Risks analysis fro HDL-C}

The level of high-density lipoprotein cholesterol (HDL-C) in the sample group was $12 \%$ lower than that of the control $(\mathrm{P}<0.01)$ shown in Table 2. HDL-C is one of the fatty components of high-density lipoprotein (HDL) which is one of the five major groups of lipoproteins enabling lipids to be transported within bloodstream. HDL particles are able to remove cholesterol from atheroma, an abnormal fatty deposit in an artery, and transport it back to the liver for excretion or re-utilization, which is the main reason why HDL-C is sometimes called good cholesterol. 


\begin{tabular}{|c|c|c|c|c|c|}
\hline Parameter & Unit & MLB-SDW & Control & P Value & Conclusion \\
\hline ALT & $U / L$ & $58.10 \pm 6.26$ & $134.80 \pm 49.03$ & 0.0001 & $P<0.01 ; \downarrow 57 \%$ \\
\hline AST & $U / L$ & $120.10 \pm 14.30$ & $187.80 \pm 53.24$ & 0.0011 & $P<0.01 ; \downarrow 36 \%$ \\
\hline Cys C & $\mathrm{mg} / \mathrm{L}$ & $0.39 \pm 0.07$ & $0.52 \pm 0.05$ & 0.0001 & $P<0.01 ; \downarrow 25 \%$ \\
\hline TG & $\mathrm{m} \mathrm{mol} / \mathrm{L}$ & $0.90 \pm 0.26$ & $4.20 \pm 1.40$ & 0.0000 & $\mathrm{P}<0.01 ; \downarrow 79 \%$ \\
\hline HDL-C & $\mathrm{m} \mathrm{mol} / \mathrm{L}$ & $1.76 \pm 0.21$ & $1.99 \pm 0.10$ & 0.0070 & $\mathrm{P}<0.01 ; \downarrow 12 \%$ \\
\hline LPS & $U / L$ & $30.20 \pm 3.65$ & $36.00 \pm 5.98$ & 0.0174 & $P<0.05 ; \downarrow 16 \%$ \\
\hline
\end{tabular}

Note: Each value in Table 1 is the mean of thirty samples

Table 2: The six biochemical parameter levels decreased by MLB-SDW-THL.

\begin{tabular}{|l|l|l|l|l|}
\hline No & Parameter & Lower-than-normal levels may be associated with & References \\
\hline 1 & ALT & reduced survival year in the elderly people, disorders in amino acid and carbonhydrate metabolism \\
\hline 2 & AST & disorders in amino acid and carbonhydrate metabolism and necrosis or disease in these tissues \\
\hline 3 & Cys C & atherosclerosis and aortic aneurysms, kidney function and deteriorating cardiovascular diseases and brain disorders & [21,9,40,34] \\
\hline 4 & TG & hyperthyroidism, malabsorption syndrome, the form of lipoproteins, energy sources and transporters of dietary fat & [10,40,34] \\
\hline 5 & HDL-C & an increased risk of atherosclerotic heart disease and non-insulin-dependent diabetes & {$[5,37,36]$} \\
\hline 6 & LPS & breakdown of fat into fatty acids, pancreas damage, familial lipoprotein lipase deficiency, a group of rare genetic disorders & {$[11,25,40]$} \\
\hline
\end{tabular}

Table 3: Potential human health risks associated with serum biochemical parameters.

Table 3 indicates that lower than normal level of HDL-C has been found that they associate with an increased risk of atherosclerotic heart disease and non-insulin-dependent diabetes $[4,10,40]$.

\section{Risks analysis for LPS}

The level of lipase (LPS) in the sample group was $16 \%$ lower than that of the control $(\mathrm{P}<0.05)$ shown in Table 2. LPS is an enzyme released by the pancreas into the small intestines. It triggers the breakdown of fat into fatty acids. It appears in the blood when the pancreas is damaged. LPS performs essential roles in the digestion, transport and processing of dietary lipids in most, if not all, living organisms.

Table 3 indicates that the decreased level of lipase is rare except a disorder called familial lipoprotein lipase deficiency due to a group of rare genetic disorders. And decreased levels of LPS might be associated with poor lipid metabolism at least. It is necessary to have further study on the effects of decreased levels of LPS on people's health $[9,40]$.

\section{Risks form organic pollutants}

The total concentration of PAHs in the water was $429.17 \mathrm{ng} / \mathrm{L}$ shown in Table 1 which was higher than the maximum permissible limit (200ng/L) listed in the Drinking Water Standards of US-EPA-2006. Di-n-butyl phthalate (DNBP) in the water was $3632 \mathrm{ng} / \mathrm{L}$, higher than the maximum permissible limit (3000ng/L) listed in the Standards for Drinking Water Quality (GB5749-2006) [26]. The data suggest that PAHs and DNBP in MLB-SDW-THL might be the important two factors at least which reduced the six biochemical parameter levels and induced the pathogenic risks.

\section{Comparison with the risks reported}

MLB-SDW-THL had low species biodiversity due to the pollution reported by Cai et al. [6] and had potential mutagenesis discovered by Gao et al. [15]. Strong indirect genomic toxicities were found in all sediment samples of MLB-SDW-THL and PAHs were one kind of the major mutagenic stressors discovered by Qiao et al. [29], Ji et al. [20] reported that the average concentrations of total microcystin-RR, LR and the extracellular microcystin-RR, LR were $1.819 \mathrm{Lg} / \mathrm{L}, 1.090 \mathrm{Lg} / \mathrm{L}$, $0.491 \mathrm{Lg} / \mathrm{L}$, and $0.077 \mathrm{Lg} / \mathrm{L}$ respectively in MLB-SDW-THL in 2007. MLB-SDW-THL also had metabonome toxicity and the toxicity of cyanobacterial bloom extracts on mouse (Mus musculus) reported by Zhang et al. [42], Li et al. [22].

All the above reports might be the evidences to illustrate that why
MLB-SDW-THL had biochemical toxicity and pathogenic risks on the mice discovered in this research.

\section{Conclusion}

Organic pollutants in MLB-SDW-THL, including PAHs and di-nbutyl phthalate at least discovered in this research, decreased the six serum biochemical parameter levels of ALT, AST, Cys C, TG, HDL-C and LPS in the sampled mice.

MLB-SDW-THL decreased the three biochemical parameters of Cys C, TG and HDL-C might induce the risks on hyperthyroidism, atherosclerotic heart diseases, noninsulin-dependent diabetes, malabsorption syndrome and metabolism systems.

MLB-SDW-THL could not be used as a source of drinking water used for Wuxi City 3 years ago because a cyanobacteria bloom happened in 2007. This research demonstrated that MLB-SDW-THL still couldn't be used as a source of drinking water to make tap water for drinking and washing after the 3 years.

The data suggested that the government for the MLB-SDWTHL area should need to take more strict measures and control the pollutants of PAHs and di-n-butyl phthalate at least for protection of human and environment health.

\section{Acknowledgements}

The financial support of this research was provided by the program of Symbol Techniques for Assessment and Predication of Environmental Risks in TaiHu Lake Area [2009ZX07528-005] in project of WEREPT-THA.

\section{References}

1. Abdul-Hussien $\mathrm{H}$, Soekhoe RG, Weber $\mathrm{E}$, von der Thüsen $\mathrm{JH}$, Kleemann $\mathrm{R}$, et al. (2007) Collagen degradation in the abdominal aneurysm: a conspiracy of matrix metalloproteinase and cysteine collagenases. Am J Pathol 170: 809-17.

2. Abisi S, Burnand KG, Waltham M, Humphries J, Taylor PR, et al. (2007) Cysteine protease activity in the wall of abdominal aortic aneurysms. J Vasc Surg 46: 1260-6

3. American Association for Clinical Chemistry (2010) Cystatin C. Lab Tests Online. US National Library of Medicine. http://www.labtestsonline.org/ understanding/analytes/cystatin_c/glance.html. Accessed 25 October 2010

4. American Heart Association. LDL and HDL Cholesterol: What's Bad and What's Good? http://www.americanheart.org/presenter.jhtml?identifier=180. Accessed 3 February 2011

5. Bertram L, McQueen M, Mullin K, Blacker D, Tanzi R (2011) The AlzGene Database. Alzheimer Research Forum. 
Citation: Yun S, Tian X, Cheng S, Zhang Y, Zhang L, et al. (2011) Risks of the Meiliang Bay Source of Drinking Water in Taihu Lake (MLB-SDW-THL) on Environmental Health. J Bioequiv Availab 3: 165-168. doi:10.4172/jbb.1000078

6. Cai YJ, Gong ZJ, Qin BQ (2010) Community structure and diversity of macrozoobenthos in Lake Taihu, a large shallow eutrophic lake in China. Biodiversity Science 18: 50-59.

7. Chan EC, Koh PK, Mal M, Cheah PY, Eu KW, et al. (2009) Metabolic profiling of human colorectal cancer using high-resolution magic angle spinning nuclear magnetic resonance (HR-MAS NMR) spectroscopy and gas chromatography mass spectrometry (GC/MS). J Proteome Res 8: 352-61.

8. Li D, Liu Z, Cui Y, Li W, Fang H, Li M, et al. (2011) Toxicity of cyanobacterial bloom extracts from Taihu Lake on mouse, Mus musculus. Ecotoxicology 20: 683-693.

9. Dugdale DC, Zieve D (2009) ALT. MedlinePlus. US National Library of Medicine.

10. Dugdale DC, Zieve D (2009) AST. MedlinePlus. US National Library of Medicine.

11. Dugdale DC, Zieve D (2010) Triglyceride level. MedlinePlus. US National Library of Medicine.

12. Dugdale DC, Zieve D (2010) HDL test. MedlinePlus. US National Library of Medicine.

13. Dugdale DC, Longstreth GF, Zieve D (2009) Lipase test, MedlinePlus. US National Library of Medicine.

14. Gacko M, Chyczewski L, Chrostek L (1999). Distribution, activity and concentration of cathepsin $B$ and cystatin $C$ in the wall of aortic aneurysm. Pol J Pathol 50: 83-6.

15. Gao XY, Cui YB, Hu ChW, Qian X, Kong ZM, et al. (2009) Genotoxicity Effect of Organic Pollutants in Meiliang Bay of Taihu Lake on Microalga Euglena gracilis. Environmental Science 30: 3388-3392.

16. Han LS, Ye J, Qiu WJ, Gao XL, Wang Y, et al. (2008) Diagnosis of inborn errors of metabolism using tandem mass spectrometry and gas chromatography mass spectrometry. Zhonghua Yi Xue Za Zhi 88: 2122-6.

17. Huang W, Chen M, Xu L (2009) A Study on Water Environment Surveillance and Early Warning System of Taihu Lake. Environmental Monitoring and Forewarning 1: 6-9.

18. IUPAC-IUB Commission on Biochemical Nomenclature (CBN) (1976). Nomenclature of Lipids.

19. Jeon YK, Kim MR, Huh JE, Mok JY, Song SH, et al. (2011) Cystatin C as an early biomarker of nephropathy in patients with type 2 diabetes. J Korean Med Sci 26: 258-63.

20. Ji RP, Li XN, Lu XW (2007) Variation of Microcystins Concentration in Source Water from Meiliang Bay, Taihu Lake. Technology for Environmental Monitoring and Management 19: 20-22.

21. Le Couteur DG, Blyth FM, Creasey HM, Handelsman DJ, Naganathan V, et a. (2010) The association of alanine transaminase with aging, frailty, and mortality. J Gerontol A Biol Sci Med Sci 65: 712-7.

22. Li TY, Huang SB, Sun F, Zha JM, Qiao M, et al. (2008) Bioaccumulation by Corbicula fluminea of polycyclic aromatic hydrocarbons from sediments in Meiliang Bay, Taihu Lake. Acta Scientiae Circumstantiae 11: 2354-2360.

23. Li WX, Zhang YC, Liu Z, Cai JB, Zhang XX, et al. (2009) Outline for establishment of the Taihu Lake Basin early warning system. Ecotoxicology 6: 768-771.

24. Maresova V, Chadt J, Novakova E (2008) Screening and semiquantitative analysis of drugs and drugs of abuse in human serum samples using gas chromatography-mass spectrometry. Neuro Endocrinol Lett 29: 749-54.

25. Merriam-Webster (2005) Merriam-Webster's Medical Desk Dictionary. Merriam-Webster, Incorporated.

26. National Standard Committee of the People's Republic of China (2006) Standards for Drinking Water Quality, GB5749-2006.

27. Paik MJ, Cho EY, Kim H, Kim KR, Choi S, et al. (2008) Simultaneous clinical monitoring of lactic acid, pyruvic acid and ketone bodies in plasma as methoxime/tert-butyldimethylsilyl derivatives by gas chromatography-mass spectrometry in selected ion monitoring mode. Biomed Chromatogr 22: 450-3.

28. Qian Y, Che JS, Liu ZH, Song QJ (2010) Preliminary Study on Organic Pollutants in Source water of Taihu Lake. J Anhui Agri Sci 17: 9361- 9362.

29. Qiao M, Wang ChX, Huang ShB, Wang ZJ (2006) Genotoxicity of organic pollutant water and sediment in Meiliang Bay, Taihu Lake, China. Environmental Science 26: 224-227.
30. Reidy L, Gennaro W, Steele BW, Walls HC (2008) The incidence of Zolpidem use in suspected DUI drivers in Miami-Dade Florida: a comparative study using immunalysis Zolpidem ELISA KIT and gas chromatography-mass spectrometry screening. J Anal Toxicol. 32: 688-94.

31. Roos JF, Doust J, Tett SE, Kirkpatrick CM (2007) Diagnostic accuracy of cystatin $C$ compared to serum creatinine for the estimation of renal dysfunction in adults and children--a meta-analysis. Clin Biochem 40: 383-91.

32. Schnabel RB, Schulz A, Messow CM, Lubos E, Wild PS, et al. (2010) Multiple marker approach to risk stratification in patients with stable coronary artery disease. Eur Heart J 31: 3024-31.

33. Schulte S, Sun J, Libby P, Macfarlane L, Sun C, et al. (2010) Cystatin C deficiency promotes inflammation in angiotensin II-induced abdominal aortic aneurisms in atherosclerotic mice. Am J Pathol 177: 456-63.

34. Shen T, Wang JY, Zhao BT (1983) Biochemistry. People's Education Press. Beijing pp529-540.

35. Shi GP, Sukhova GK, Grubb A, Ducharme A, Rhode LH, et al. (1999) Cystatin C deficiency in human atherosclerosis and aortic aneurysms. J Clin Invest 104 1191-7.

36. Shlipak MG (2007) Cystatin C as a marker of glomerular filtration rate in chronic kidney disease: influence of body composition. Nat Clin Pract Nephrol 3: 188-9.

37. Taglieri N, Koenig W, Kaski JC (2010) Cystatin C and cardiovascular risk. Ann Biol Clin (Paris). 68: 517-29.

38. Thiel V, Vilchez R, Sztajer H, Wagner-Döbler I, Schulz S (2009) Identification, quantification, and determination of the absolute configuration of the bacterial quorum-sensing signal autoinducer- 2 by gas chromatography-mass spectrometry. Chembiochem 10: 479-85.

39. Van Thuyne W, Van Eenoo P, Delbeke FT (2008) Implementation of gas chromatography combined with simultaneously selected ion monitoring and ful scan mass spectrometry in doping analysis. J Chromatogr A 1210: 193-202.

40. Venes D, Biderman A, Adler E, Fenton BG (2001) Taber's cyclopedic medical dictionary, 20th edn. F. A. Davis Company, Philadelphia

41. Wang HL, Zhong RQ, Chen LM, Li P, Wu JM, et al. (2005) Laboratory Diagnosis, $5^{\text {th }}$ edition. People's Sanitation Press, Beijing, p. 160.

42. Zhang Y, Wu B, Zhang ZY, Cheng SP (2011) A metabonomic analysis on health effects of drinking water on male mice (Mus musculus). J Hazard Mater 190: $515-519$.

43. Zhang Y, Li W, Sun J, Zhang R, Wu B, et al. (2011) NMR-based metabolic profiling for serum of mouse exposed to source water. Ecotoxicology 20: 16051670.

44. Zhao JL, Ying GG, Wang L, Yang JF, Yang XB, et al. (2009) Determination of phenolic endocrine disrupting chemicals and acidic pharmaceuticals in surface water of the Pearl Rivers in South China by gas chromatography-negative chemical ionization-mass spectrometry. Sci Total Environ 407: 962-74. 